\title{
System Characterization of Earth Observation Sensors
}

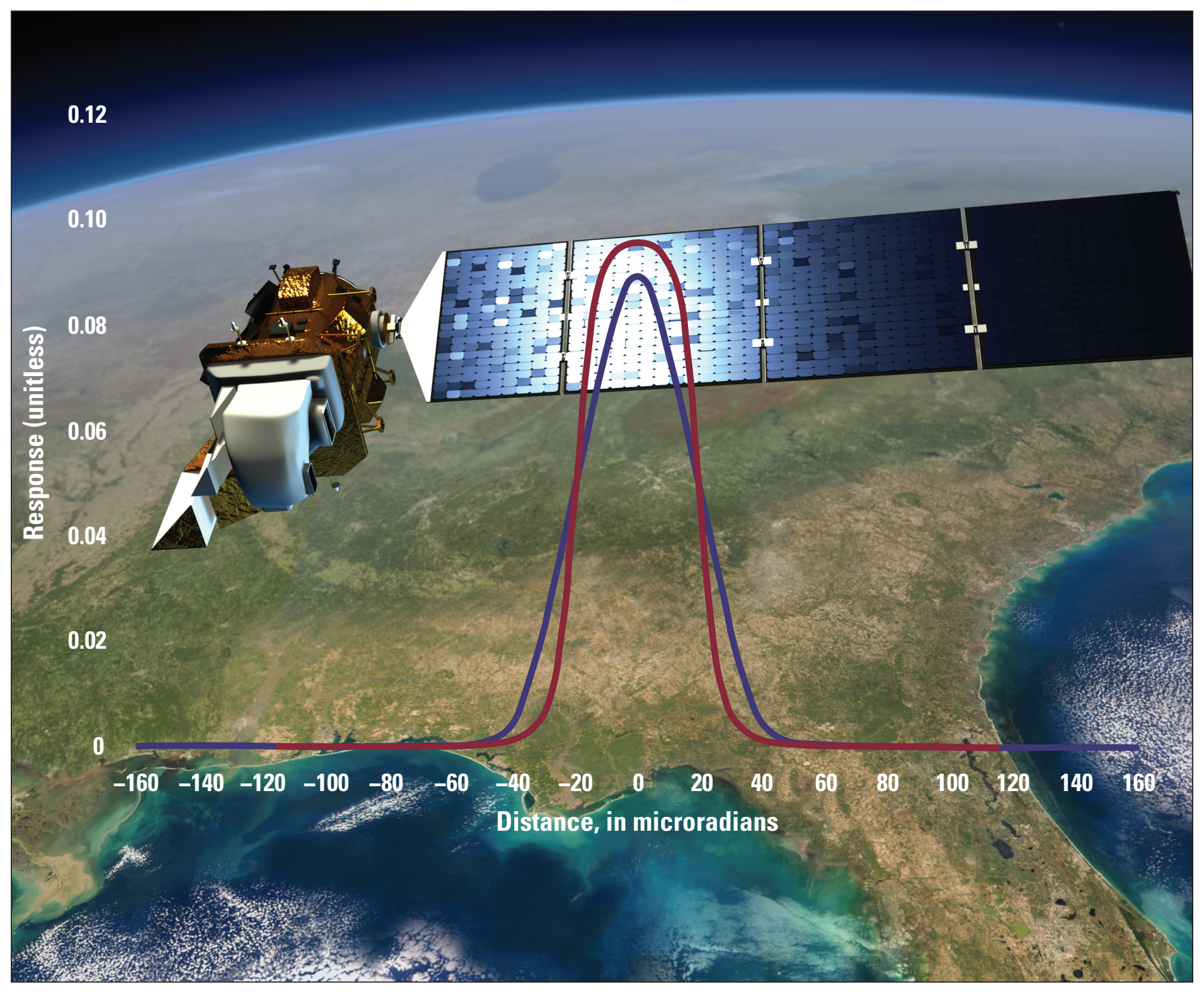

Open-File Report 2021-1030 
Cover: Artist concept of Landsat 8. Image courtesy of National Aeronautics and Space Administration's Goddard Space Flight Center. Graph shows across-track (red line) and alongtrack (blue line) line spread functions for Landsat 80 perational Land Imager band 3 (green). Image courtesy of the U.S. Geological Survey. 


\section{System Characterization of Earth Observation Sensors}

Compiled by Shankar N. Ramaseri Chandra ${ }^{1}$

${ }^{1} \mathrm{KBR}$, Inc., under contract to the U.S. Geological Survey.

Open-File Report 2021-1030

U.S. Department of the Interior

U.S. Geological Survey 


\section{U.S. Geological Survey, Reston, Virginia: 2021}

For more information on the USGS - the Federal source for science about the Earth, its natural and living resources, natural hazards, and the environment-visit https://www.usgs.gov or call 1-888-ASK-USGS.

For an overview of USGS information products, including maps, imagery, and publications, visit https://store.usgs.gov/.

Any use of trade, firm, or product names is for descriptive purposes only and does not imply endorsement by the U.S. Government.

Although this information product, for the most part, is in the public domain, it also may contain copyrighted materials as noted in the text. Permission to reproduce copyrighted items must be secured from the copyright owner.

\section{Suggested citation:}

Ramaseri Chandra, S.N., comp., 2021, System characterization of Earth observation sensors: U.S. Geological Survey Open-File Report 2021-1030, [variously paged], https://doi.org/10.3133/ofr20211030.

ISSN 2331-1258 (online) 


\section{Contents}

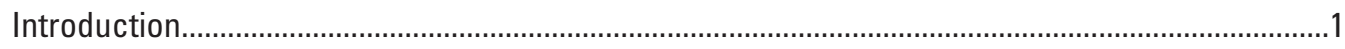

Earth Resources Observation and Science (EROS) and EROS Cal/Val Center of

Excellence ............................................................................................................

Requirements, Capabilities, and Analysis for Earth Observation ...........................................

Joint Agency Commercial Imagery Evaluation ......................................................................

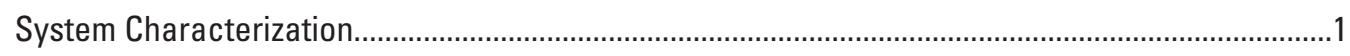

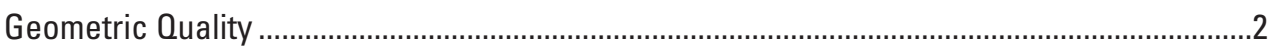

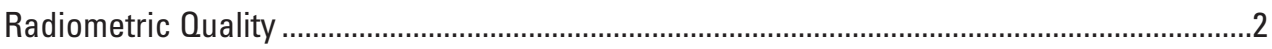

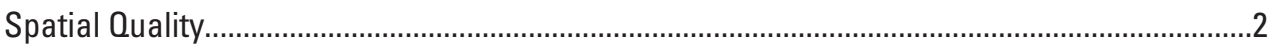

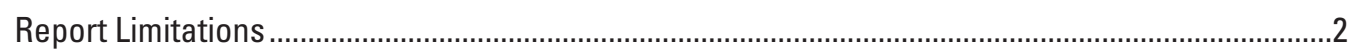

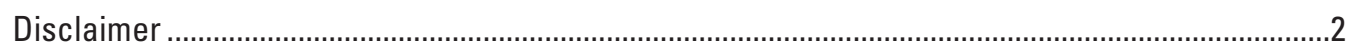

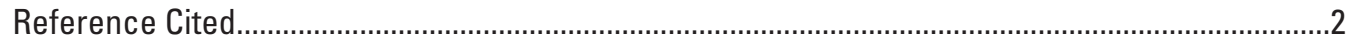

\section{Abbreviations}

ECCOE EROS Cal/Val Center of Excellence

EROS Earth Resources Observation and Science

JACIE Joint Agency Commercial Imagery Evaluation

NLIP National Land Imaging Program

RCA-EO Requirements, Capabilities, and Analysis for Earth Observation

SNR signal-to-noise ratio

USGS U.S. Geological Survey 



\title{
System Characterization of Earth Observation Sensors
}

\author{
By Shankar N. Ramaseri Chandra, ${ }^{1}$ Jon B. Christopherson, ${ }^{1}$ Simon J. Cantrell, ${ }^{1}$ Cody Anderson, ${ }^{2}$ and Gregory \\ L. Stensaas ${ }^{2}$
}

\section{Introduction}

This U.S. Geological Survey (USGS) Open-File Report provides information from assessments of Earth observation sensors completed by the USGS. These reports are provided as independent measures of basic system performance.

The USGS has a long history of supporting land remote sensing in the civil and commercial sectors. Since the late 1960s, the USGS has helped to conceive of, and actively promote, what has become the Landsat series of satellites, working with international cooperators on the Landsat program since 1973. The USGS has promoted the sharing and use of remotely sensed data to support science and applications to better understand the Earth. The USGS National Land Imaging Program (NLIP) has a responsibility to provide imagery for the Nation in support of science, land management, and other needs. The USGS NLIP operates the Landsat series of satellites and has had continuous involvement in the planning and operation of Earth remote sensing for more than 50 years.

\section{Earth Resources Observation and Science (EROS) and EROS Cal/Val Center of Excellence}

The USGS Earth Resources Observation and Science (EROS) Cal/Val Center of Excellence (ECCOE) is funded by the USGS NLIP. ECCOE was established with the overarching goal of improving the accuracy, precision, and interoperability of optical remote sensing systems. ECCOE development provides access to tools, algorithms, and interfaces that enhance data access and exploitation for analysis. ECCOE is responsible for maintaining the Landsat archives and calibration of the Landsat satellites.

\section{Requirements, Capabilities, and Analysis for Earth Observation}

To understand the user needs for Earth observation, measurement, and monitoring, the Requirements, Capabilities, and Analysis for Earth Observation (RCA-EO) Project was

\footnotetext{
${ }^{1}$ KBR, Inc., under contract to the U.S. Geological Survey.

${ }^{2}$ U.S. Geological Survey.
}

established. As a key project under ECCOE, one of the missions of the RCA-EO Project is to identify and catalog existing and planned capabilities for measuring and monitoring the Earth. The assessments presented in this report are used in the context of RCA-EO to better understand the capabilities of orbiting systems and their potential utility to science and other applications.

\section{Joint Agency Commercial Imagery Evaluation}

In 2000, the USGS and several partner agencies founded the Joint Agency Commercial Imagery Evaluation (JACIE), an interagency partnership, to assess the quality and explore the potential utility of newly launched commercial high-resolution satellites. The JACIE partnership has continued since then and has expanded its scope to include all commercial and civil imaging systems. These system characterization reports are part of the USGS contribution to the JACIE partnership.

Before the 2020 characterizations, all ECCOE characterizations were shared through presentations at JACIE and not in a USGS Open-File Report. These earlier presentations, as well as all other presentations given at JACIE, are available through the ECCOE website at https://www.usgs.gov/corescience-systems/eros/calval/past-jacie-workshops.

The ECCOE project, and the associated system characterization process used for this assessment, follows the USGS Fundamental Science Practices, which include maintaining data, information, and documentation needed to reproduce and validate the scientific analysis documented in this report. Additional information and guidance about Fundamental Science Practices and related resource information of interest to the public are available at https://www.usgs.gov/ about/organization/science-support/office-science-qualityand-integrity/fundamental-science-practices. For additional information related to the report, please contact ECCOE at eccoe@usgs.gov.

\section{System Characterization}

Each of the systems characterized within this report were selected by the ECCOE management after consideration of available systems and their potential interest to the USGS 
NLIP. In some cases, data were freely available to the public, but often the USGS obtained data through cooperation with the operator/vendor of that satellite and its data system. The USGS is grateful for this cooperation in advancing its knowledge and understanding of the capabilities of the growing remote sensing community.

Once data are obtained for assessment, the USGS completes an initial assessment to understand the unique characteristics of the data and their completeness. After this initial assessment, the data are evaluated for their geometric, radiometric, and spatial quality.

\section{Geometric Quality}

Geometric quality assessment of a remote sensing product independently assesses the geometric characteristics of the imagery. For a multispectral or hyperspectral (multiband) remote sensing product, the assessment involves two kinds of validation, internal and external geometry. The internal geometric assessment measures the relative band-to-band registration accuracy, determining how closely the pixels from each spectral band align with corresponding pixels from the other bands within the product. The external geometric assessment evaluates the absolute positional accuracy of the image products with respect to ground (geodetic) reference. The geodetic ground reference is chosen based on known positional accuracy and internal geometric consistencies, which are typically better than the images being evaluated. External geometric performance is given as relative to another image source, one chosen for its known and generally high accuracy, or as an absolute measurement when the imagery under test is assessed against ground control points of surveyed accuracy.

\section{Radiometric Quality}

Radiometric quality assessment measures the accuracy of the radiance or reflectance reported by the system tested. The accuracy is measured in two ways. Often, the imagery under test is compared to the radiance/reflectance of a reference image product from another system of known high accuracy and of similar spectral properties to the imagery in evaluation. In other cases, the imagery under test is assessed against known ground targets, such as Pseudo Invariant Calibration Sites or instrumented ground sites (for example, Radiometric Calibration Network), which have known radiance/reflectance for comparison (Helder and others, 2013).

A closely related measurement of radiometric performance is the level of spurious signal or "noise" within the image. This is known as the signal-to-noise ratio (SNR). Not all assessments contain SNR measurements because the measurements are highly dependent on the imagery and targets imaged and sometimes cannot be made with confidence given the imagery available to the USGS.

\section{Spatial Quality}

Often, the spatial resolution of remotely sensed imagery is described in terms of pixel spacing or ground sample distance. Although substantial, ground sample distance is only one aspect of spatial resolution. The optical detectors may have some amount of "blur," or lack of sharpness. Spatial characterization provides a quantification of that sharpness/ blur. For the assessments within this report, spatial characterization is most commonly measured using edge targets or bridges, both chosen to provide known input to the system. It should be noted that low SNR, as described previously, can also negatively affect the apparent resolution of an image.

\section{Report Limitations}

The assessments contained within each chapter are accurately reported and faithful to the results of the imagery tested by the USGS. They are a "snapshot in time" of the imagery available to the USGS at the time of testing. Data products generated before or after those tested by the USGS may have different characteristics.

The USGS tests only a small sample of the products available from a mission archive. These products are chosen and assumed to be a representative sample; however, differences may be detected in a wider selection of the data product.

Anyone wishing to discuss these reports should contact the USGS EROS ECCOE project at eccoe@usgs.gov.

\section{Disclaimer}

The USGS does not endorse any specific sensor by virtue of its inclusion or omission in this report.

\section{Reference Cited}

Helder, D., Thome, K.J., Mishra, N., Chander, G., Xiong, X., Angal, A., and Choi, T., 2013, Absolute radiometric calibration of Landsat using a pseudo invariant calibration site: IEEE Transactions on Geoscience and Remote Sensing, v. 51, no. 3, p. 1360-1369. [Also available at https://doi.org/ 10.1109/TGRS.2013.2243738.] 
For more information about this publication, contact: Director, USGS Earth Resources Observation and Science Center 47914 252nd Street

Sioux Falls, SD 57198

605-594-6151

For additional information, visit: https://www.usgs.gov/centers/eros

Publishing support provided by the

Rolla Publishing Service Center 


\section{$\frac{\mathbb{2}}{3}$}

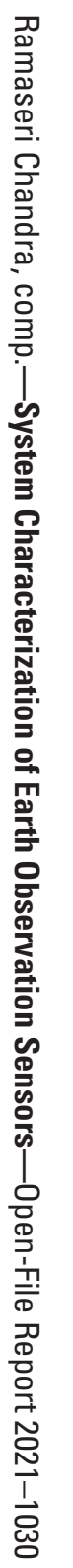

